\title{
A PRÁTICA DO SERVIÇO DE REFERÊNCIA EM UMA BIBLIOTECA UNIVERSITÁRIA À LUZ DA TEORIA DE CRIAÇÃO DO CONHECIMENTO ORGANIZACIONAL DE NONAKA E TAKEUCHI
}

Josiana Florêncio Vieira Régis
de Almeida
Mestre em Engenharia de Produção
pela Universidade Federal do Rio
Grande do Norte. Bibliotecária
Documentalista na Universidade
Federal do Rio Grande do Norte.
E-mail: josianavieira@gmail.com
Josiane Mello
Doutoranda em Ciência da Informação
pela Universidade Federal de Santa
Catarina. Bibliotecária Documentalista
na Universidade Federal do Rio Grande
do Norte.
E-mail: josianemelloci@gmail.com

Josiana Florêncio Vieira Régis de Almeida

Mestre em Engenharia de Produção pela Universidade Federal do Rio Grande do Norte. Bibliotecária Documentalista na Universidade Federal do Rio Grande do Norte.

Josiane Mello pela Universidade Federal de Santa Catarina. Bibliotecária Documentalista do Norte.

\section{RESUMO}

Apresenta um estudo realizado em uma biblioteca universitária, do Estado do Rio Grande do Norte, com o objetivo de estudar o serviço de referência a luz da teoria de criação do conhecimento organizacional de Nonaka e Takeuchi, também denominada por estes autores de Espiral do conhecimento. Trata-se de uma pesquisa descritiva, com abordagem qualitativa, na qual se fez uso do procedimento técnico: estudo de caso. 0 instrumento de coleta de dados empregado foi um questionário, adaptado de Rostirolla (2009), composto por questões de múltipla escolha e questões abertas. Os resultados desse estudo revelaram o conhecimento, resultante de um processo constante de interação, para ser ampliado, necessita ser compartilhado e difundido entre a equipe estudada. As fontes de informação são ótimos meios de aquisição de conhecimentos. A conversão do conhecimento tácito e explícito auxilia no êxito da efetivação da atividade de serviço de referência. As ferramentas da tecnologia da informação e comunicação contribuem na comunicação, colaboração e interação entre os membros da equipe na medida em que possibilitam a troca de informações, ideias e experiências, alavancando assim, o processo de criação de conhecimento.

Palavras-chave: Conhecimento organizacional. Biblioteca universitária. Serviço de referência. Espiral do conhecimento. Nonaka e Takeuchi.

PRACTICE OF REFERENCE SERVICE IN A LIBRARY UNIVERSITY THE LIGHT OF THE THEORY OF CREATION OF ORGANIZATIONAL KNOWLEDGE NONAKA AND TAKEUCHI 


\begin{abstract}
Presents a study in a university library, the State of Rio Grande do Norte, in order to study the reference service the light of the theory of organizational knowledge creation of Nonaka and Takeuchi, also known by these authors knowledge spiral. This is a descriptive research with a qualitative approach, which made use of the technical procedure: a case study. The employee data collection instrument was a questionnaire adapted from Rostirolla (2009), composed of multiple choice questions and open questions. The results of this study revealed knowledge, resulting in a constant process of interaction to be expanded, it needs to be shared and distributed among the study team. Information sources are great means of acquiring knowledge. The conversion of tacit and explicit knowledge aids in the successful execution of the reference service activity. The tools of information and communication technology contribute to the communication, collaboration and interaction among employees in that it enables the exchange of information, ideas and experiences, leveraging the process of knowledge creation.
\end{abstract}

Keywords: Organizational knowledge. University library. Reference service. Knowledge spiral. Nonaka and Takeuchi.

\title{
1 INTRODUÇÃo
}

A partir da década de 1980, o mundo vem enfrentando rápidas e significativas mudanças de ordem econômica, social, tecnológica e ambiental. Tais mudanças são decorrentes do fenômeno desenfreado da globalização, da valorização do capital intelectual, do advento, facilidade e eficiência das novas tecnologias de informação e comunicação (TICs) e dos desequilíbrios provocados pelo homem na natureza.

Essas alterações nos parâmetros da sociedade capitalista fizeram com que esta se reinventasse, dando origem a uma nova sociedade, designada por várias denominações, tais como: Sociedade Pós-Moderna (LYOTARD, 1979), Sociedade Pós-Capitalista (DRUCKER, 1994), Sociedade da Modernidade Tardia (GIDDENS, 1991; HALL, 2001), Sociedade Hipermoderna (LIPOVETKSY, 2004), Sociedade Pós-Industrial (DE MASI, 2006); Sociedade em Rede (CASTELLS, 2003), Sociedade da Informação (TOURAINE, 1969; BELL, 1973 apud GOUVEIA, 2004), Sociedade Líquida (BAUMAN, 2007) e Sociedade do Conhecimento (MACHLUP, 1962). Independente da denominação, o que se percebe é que a informação e o conhecimento são o bem mais precioso nesta sociedade. 
É oportuno frisar que alguns autores como Ramos (1989) consideram as pessoas como o elemento mais importante das organizações. Contudo, neste artigo, compartilhase do pensamento de Stewart (1998), o qual afirma que o conhecimento assumiu um papel dominante em nossa economia, em nossas empresas e no nosso trabalho, sendo mais importante que a matéria-prima ou até mesmo o dinheiro. Assim, o conhecimento e a informação são considerados produtos econômicos mais valiosos que o aço, automóveis, equipamentos ou qualquer outro produto da Era Industrial.

Isso não é diferente nas unidades de informação, estas para atenderem as necessidades informacionais de seus usuários, precisam pensar em novas propostas de gestão de suas operações e de avaliação da qualidade dos produtos e serviços oferecidos. E nestas ações, o conhecimento se faz presente como o maior recurso gerador de vantagem competitiva.

Neste contexto, desenvolveu-se esta pesquisa numa biblioteca universitária, do Estado do Rio Grande do Norte, com o objetivo geral de estudar como ocorre a criação do conhecimento organizacional durante a atividade de serviço de referência, a luz da teoria de criação do conhecimento organizacional de Nonaka e Takeuchi.

Para o alcance deste objetivo, estabeleceram-se os seguintes objetivos específicos: conhecer as fontes de informação internas e externas (formais e informais) utilizadas pela equipe que atua no serviço de referência para responder as questões apontadas pelos usuários; identificar quais são os conhecimentos e habilidades necessárias para a atuação plena no serviço de referência; verificar como ocorre a conversão do conhecimento tácito para explícito, apoiado nos 4 modos de conversão: socialização, externalização, combinação e internalização no âmbito da prática do serviço de referência e, por fim, identificar as condições e fatores que interferem no processo de criação de conhecimento durante a atividade de serviço de referência

Diante da impossibilidade de aplicar esta pesquisa em todos os setores da referida unidade de informação, optou-se pelo setor de referência, tendo em mente o objetivo e a importância deste serviço na atualidade, haja vista que as demandas por informação estão cada vez mais crescentes, em função de sua capacidade transformadora na sociedade.

Assim, justifica-se esta pesquisa, com o entendimento de que os bibliotecários e demais profissionais que atuam no setor de referência, durante o exercício desta atividade, desenvolvem e acumulam uma série de conhecimento sobre as mais variadas 
fontes de informações, base de dados, estratégias de buscas, processos de busca, e entre outros meios de se chegar às respostas dos problemas apontados pelos usuários.

É oportuno pontuar também, que tais expertises não podem ser exclusivas de apenas um ou alguns membros da equipe de trabalho, pois em caso de ausência, substituição ou algum outro motivo, será impossível dar continuidade às tarefas préestabelecidas, impedindo que o serviço de referência seja realizado de maneira efetiva.

A metodologia empregada para realização desta pesquisa foi pautada em sua caracterização, que é qualitativa, descritiva e estudo de caso. O instrumento de coleta de dados empregado foi um questionário, adaptado de Rostirolla (2009), composto por questões de múltipla escolha e questões abertas.

O presente artigo está estruturado em mais seis seções, além desta introdução. A segunda e terceira apresentam o referencial teórico. A quarta seção descreve a metodologia empregada. A quinta seção aborda a análise dos dados, seguida das considerações finais e referências.

\section{DADO, INFORMAÇÃO E CONHECIMENTO}

Para abordar o processo de criação de conhecimento, é oportuno, primeiramente, fazer uma distinção entre o significado de dado, informação e conhecimento, pois de acordo com alguns autores, dentre os quais Davenport e Prusak (2003) e Santos (2005), há certa tendência de se utilizar os termos dados, informação e conhecimento como sinônimos.

Assim, Robbins (2000, p. 151), define dados como "fatos crus, não analisados, como números, nomes ou quantidades". Para Davenport e Prusak (2003, p.2) "dados são um conjunto de fatos distintos e objetivos, relativos a eventos". Não apresentam significado inerente. Os dados descrevem apenas uma parcela dos acontecimentos; não fornecem julgamento, interpretação e nem base para a tomada de decisão sustentável. Todavia, eles são importantes para as organizações, pois se constituem em matériaprima essencial para a criação de informação. Já no que concerne à informação, os mesmos autores pontuam que "a informação tem por finalidade mudar o modo de como o destinatário vê algo, exercer algum impacto sobre seu julgamento e comportamento. A informação não só "da forma” ao receptor como visa a alguma finalidade”.

Neste sentido, a informação possui relevância e propósito, sendo organizada 
para atender a alguma finalidade, constituindo-se em "matéria-prima para gerar conhecimento que é a informação valiosa para as organizações específicas" (GREENWOOD, 1985 apud SHIN; HOLDEN; SCHMIT, 2001, p. 336).

Sobre conhecimento, Davenport e Prusak (2003) afirmam que não existe uma definição final e apresentam a seguinte definição tachada de funcional ou pragmática:

Conhecimento é uma mistura fluida de experiência condensada, valores, informação contextual e insight experimentado, a qual proporciona uma estrutura para a avaliação e incorporação de novas experiências e informações. Ele tem origem e é aplicado na mente dos conhecedores. Nas organizações, ele costuma estar embutido não só em documentos ou repositórios, mas também em rotinas, processos, práticas e normas organizacionais (DAVENPORT; PRUSAK, 2003, p. 6).

Finalmente, pode-se considerar que dados são constituídos por simples observações de determinados fenômenos, sendo facilmente estruturados, quantificáveis, transferíveis e sua obtenção não exige mediação humana. Trata-se de números ou códigos "brutos" e "soltos", os quais não são tabulados e, por isso, não fornecem julgamento nem interpretação. Informações são dados constituídos de significados, pois são tratados e analisados, o que implica dizer que exige mediação humana. Por fim, conhecimento é a resultante da combinação de informação, valores e vivência individual. Em outras palavras, significa dizer que, o conhecimento é difícil de ser estruturado e transferido, pois é fruto da mente (tácito). E exige mediação humana, incluindo análise e contexto.

O conhecimento na visão de Nonaka e Takeuchi (1997), classifica-se em dois tipos: conhecimento tácito e conhecimento explícito. 0 conhecimento tácito resulta dos processos de análise das informações, dos insights subjetivos e da intuição e é difícil de ser externalizado. Já o conhecimento explícito pode ser formalizado, sistematizado e facilmente comunicável. Pode ser compartilhado sob a forma de dados brutos, fórmulas científicas, procedimentos codificados ou princípios universais. Sendo adquirido, principalmente, por meio de educação formal.

Assim, quando o conhecimento tácito não é transformado em conhecimento explícito e disseminado na organização, este fica restrito a um membro ou pequeno grupo de pessoas, "o que, em determinado momento, pode fazer com que a organização despenda esforços para saber algo, ou recuperar um conhecimento que já sabe" (FRANCISCO, 2003, p.20). 


\subsection{Gestão do conhecimento: conceitos e objetivos}

O processo de criação do conhecimento é um processo explorado pela Gestão do Conhecimento. Neste sentido, antes de abordar a teoria de criação do conhecimento organizacional de Nonaka e Takeuchi faz-se necessário apresentar um recorte conceitual da referida temática.

Sobre isto, Martensson (2000) afirma que a literatura sobre Gestão do Conhecimento está dirigida principalmente à questão do capital intelectual, da inovação e da geração de competências, que, em suma, voltam-se à ideia de conhecimento como geração de valor. De acordo com Davenport e Prusak (2003, p.61), a gestão do conhecimento é "o conjunto de atividades relacionadas à geração, codificação e transferência do conhecimento", baseia-se em aperfeiçoar os recursos disponíveis na organização de forma orientada para o conhecimento.

Para Choo (2006, p.17) a gestão do conhecimento pode dotar as organizações de competências e habilidades capazes de gerar mais qualidade em seus processos, rotinas, experiências e se adaptarem às "constantes mudanças, de inovar continuamente e de tomar decisões que as levam em direção a seus objetivos".

Bukowitz e Williams (2002) apontam as tecnologias de informação e comunicação, como uma das principais forças que levaram a gestão do conhecimento para o primeiro plano e para o centro das organizações. Sveiby (2008) define Gestão do Conhecimento como a arte de criar valor a partir dos ativos intangíveis. Quanto aos objetivos da implantação de um Sistema de Gestão do Conhecimento, Davenport e Prusak (2003) afirmam que tal ação objetiva possibilitar que os membros de uma organização compartilhem conhecimentos e informações.

Nesta concepção, Nascimento e Neves (1999, p.3) ressaltam que em um Sistema de Gestão do Conhecimento a "liberdade, criatividade, incentivo ao estudo, ao compartilhamento, transferência e criação de novos conhecimentos criam ambientes que, sustentados pela tecnologia, acenam com oportunidades de crescimento e retorno para todos". 


\subsection{A teoria de criação de conhecimento de Nonaka e Takeuchi - a espiral do conhecimento}

Para compor a base da teoria da criação do conhecimento organizacional, Nonaka e Takeuchi (1997) resgatam a tipologia de conhecimento de Polanyi (1966). Tal teoria também é conhecida por Espiral do Conhecimento.

Para estes autores, o conhecimento é criado através da interação entre o conhecimento tácito e o conhecimento explícito, por meio de 4 modos de conversão do conhecimento, a saber: socialização, externalização, combinação e internalização.

Socialização (de tácito para tácito): é o processo no qual as experiências baseadas em modelos mentais ou habilidades pessoais são compartilhadas visando à criação de novos conhecimentos tácitos. A socialização ocorre por meio de atividades, treinamentos, interações com clientes, sessões informais, brainstorms, etc.

Externalização (de tácito para explícito): o conhecimento tácito é convertido em explícito na forma de metáforas, analogias, conceitos, hipóteses ou diálogos. A externalização é a chave para a criação do conhecimento, pois cria modelos novos e explícitos a partir do conhecimento tácito.

Combinação (de explícito para explícito): nesta fase ocorre a análise, categorização e reconfiguração das informações, por meio da qual as tecnologias, as informações (intranet, internet, banco de dados) transformam as informações em novos conhecimentos.

Internalização (de explícito para tácito): este modo de conversão do conhecimento obedece à filosofia do "aprender fazendo". A verbalização e a diagramação sob a forma de documentos, manuais ou histórias orais são de extrema relevância. Através da documentação serão relatadas as experiências dos indivíduos para que sejam incorporadas à sua base de conhecimento. Após a incorporação do conhecimento, destaca-se a necessidade da socialização do conhecimento tácito obtido com outros membros da organização, iniciando assim uma nova espiral de criação de conhecimentos.

A espiral do conhecimento de Nonaka e Takeuchi é assim representada, conforme figura 1: 
Figura 1 - A espiral do conhecimento

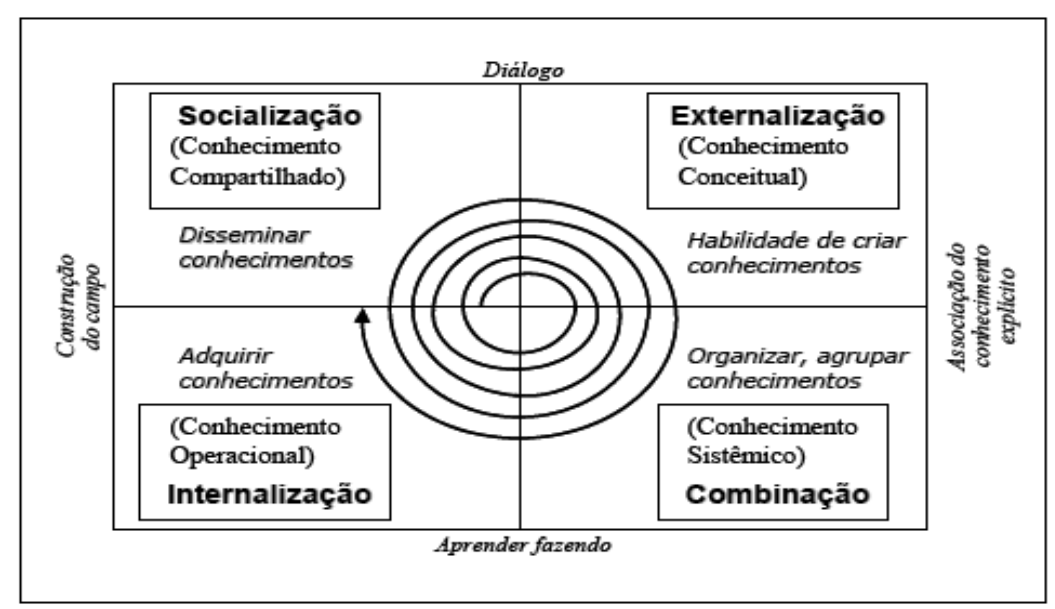

Fonte: Adaptado de Nonaka e Takeuchi (1997, p.80)

Assim, entende-se que a criação do conhecimento é um processo em espiral, que começa com a socialização. Esse conhecimento tácito criado é articulado e explicitado pela fase de externalização e passa a compor a base conceitual para a criação de novos conhecimentos sob o suporte de imagens, áudio e documentos. Esse conhecimento explícito é combinado por meio de reuniões e somado aos conhecimentos que o indivíduo já possui, sendo editado e processado gerando conhecimentos explícitos mais complexos ou sistematizados e disseminado na organização para ser internalizado e aplicado em experiências e compor a base cognitiva para novos processos, tornando-o ativos valiosos.

Para proporcionar a criação do conhecimento organizacional, o conhecimento tácito acumulado precisa ser socializado com os outros membros da organização, aumentando assim o campo do conhecimento e iniciando uma nova espiral de criação do conhecimento. 0 conteúdo do conhecimento criado por cada modo de conversão é diferente um do outro. Esses conteúdos interagem entre si na espiral de criação do conhecimento.

\subsection{Condições e fatores que fomentam a criação do conhecimento organizacional}

O grande desafio das organizações concentra-se em oferecer um contexto apropriado para a criação e compartilhamento de conhecimento organizacional. Tal contexto deve ser "apropriado para facilitação das atividades em grupo e para criação e acúmulo de conhecimento em nível individual" (NONAKA; TAKEUCHI, 2008, p. 71). 
Para que as organizações criem conhecimento, faz-se necessário atender a cinco condições. Segundo Nonaka e Takeuchi (2008), essas condições são:

Intenção: refere-se ao engajamento da organização na intenção de criar conhecimento, direcionando suas estratégias e metas organizacionais para tal.

Autonomia: diz respeito às oportunidades inesperadas como ideias individuais que se transformam em ideias organizacionais, através da autonomia de ação dos membros da organização. A autonomia permite um maior grau de flexibilidade ao adquirir, interpretar e relacionar informações, tornando os funcionários automotivados.

Flutuação e caos criativo: promovem a interação entre a organização e o ambiente externo. A flutuação provoca nos funcionários momentos de percepção envoltos em desconforto, induzindo-os ao diálogo e à reflexão no intuito de promover uma análise quanto ao pensamento e perspectivas em relação as suas atitudes básicas. O caos pode ser natural (crise real) ou intencional, também denominado de "caos criativo" (gerado pelos líderes com o objetivo de emitir um sentido de crise aos funcionários). Esse processo promove a criatividade e permite à organização a criação de novos conhecimentos.

Redundância: é a existência de informações que ultrapassam as exigências ocasionando o "aprendizado por instrução", acelerando então o processo de criação de conhecimento. A redundância estimula o diálogo com frequência e a comunicação, sendo de responsabilidade dos gestores e permite a construção de novos canais de comunicação, enfatizando a troca de conhecimentos tácitos entre os membros da organização.

Requisito variedade: baseia-se no princípio de que a diversidade interna deve ser condizente à variedade e complexidade do ambiente externo de modo que ela supere os desafios deste ambiente. Tal ação deve permitir a combinação de informações que, por sua vez, deve ser otimizada a todos os membros da organização.

Para explicar a teoria de criação do conhecimento organizacional, Nonaka e Takeuchi $(1997,2008)$, propõem um modelo composto por cinco fases, que são: (1) compartilhamento do conhecimento tácito; (2) criação de conceitos; (3) justificação de conceitos; (4) construção de arquétipos; e (5) difusão interativa do conhecimento, conforme figura 2. 
Figura 2 - Modelo de cinco fases do processo de criação do conhecimento

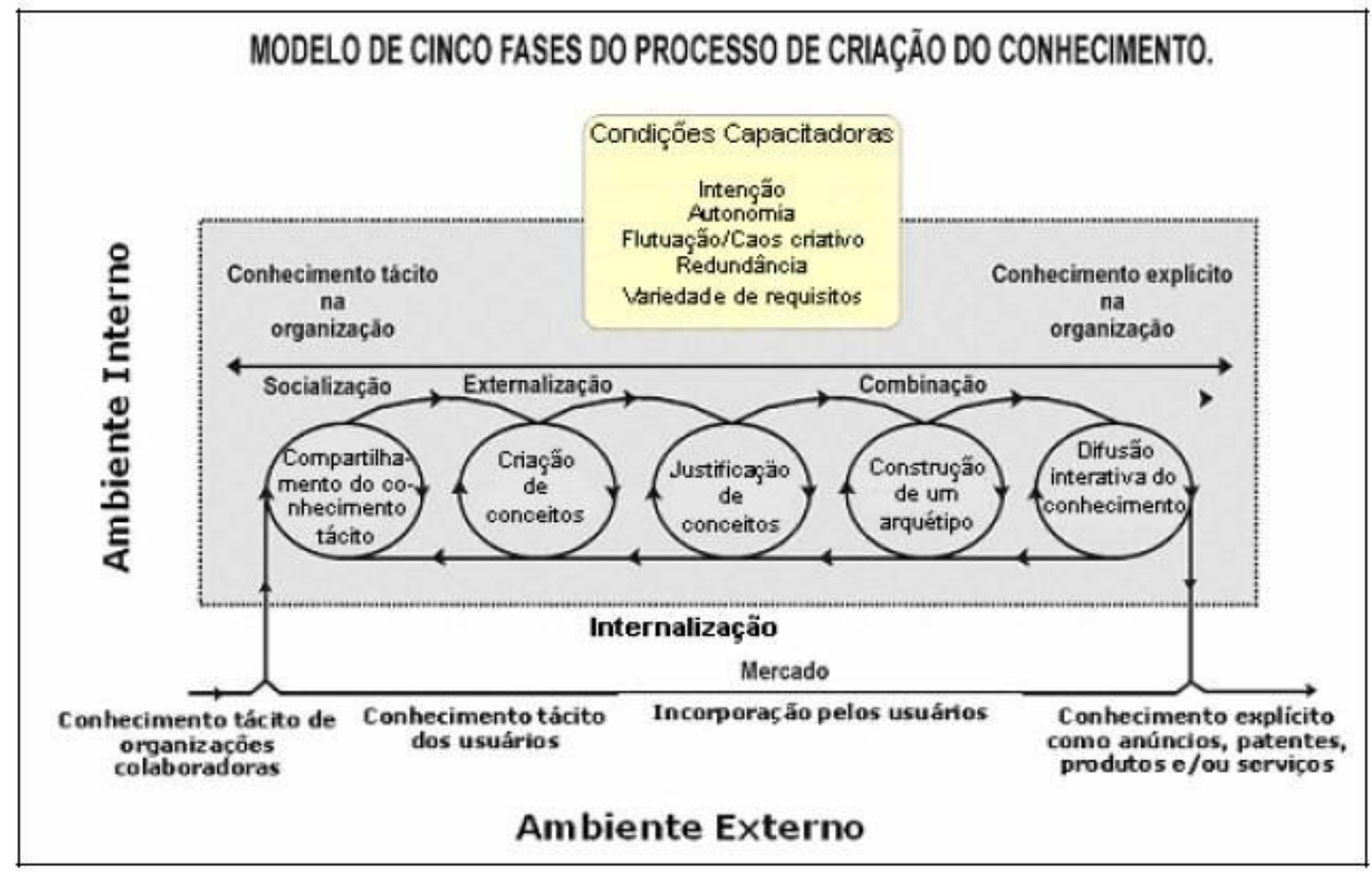

Fonte: Nonaka e Takeuchi (1997, p.96)

Com base neste modelo, Nonaka e Takeuchi (2008) alegam que o processo de criação do conhecimento organizacional inicia-se com o compartilhamento do conhecimento tácito (socialização). Já na segunda fase, o conhecimento tácito compartilhado é convertido em conhecimento explícito na forma de um novo conceito, num processo semelhante à externalização. 0 conceito criado, precisa ser justificado na terceira fase, na qual a organização reflete sobre a sua importância. Na quarta fase, recebida a confirmação dos novos conceitos, eles são convertidos em algo concreto (tangível), que podem assumir várias formas. A última fase amplia o conhecimento criado em outros grupos ou até aos componentes externos, constituindo o que chamamos de difusão interativa do conhecimento.

\section{SERVIÇO DE REFERÊNCIA EM UMA BIBLIOTECA UNIVERSITÁRIA}

As bibliotecas universitárias são espaços que adquirem, armazenam, organizam, disponibilizam e disseminam informação científica e tecnológica, atendendo às necessidades informacionais da comunidade acadêmica e da sociedade na qual está inserida. Entende-se que o processo de referência em bibliotecas universitárias carece de uma análise na perspectiva da gestão do conhecimento para subsidiar propostas de 
melhorias quanto à identificação, aquisição, desenvolvimento, compartilhamento, utilização e retenção do conhecimento dos bibliotecários que atuam neste processo (ROSTIROLLA, 2006).

Para atender às demandas informacionais de seus usuários, os profissionais destas bibliotecas, em especial os bibliotecários, desenvolvem atividades de administração (direção), seleção, aquisição e processamento técnico de materiais, implantação e gestão de repositórios institucionais, restauração dos materiais bibliográficos e atendimento ao usuário, no qual este último abarca o serviço de referência.

O serviço de referência pode variar quanto aos seus objetivos e quanto à sua profundidade, dependendo do tipo de biblioteca onde se realiza, ou seja, de acordo com as características e as finalidades da biblioteca. Ademais, os métodos de proporcionar serviços de referência aos consulentes dependem também de circunstâncias individuais e das diretrizes de cada biblioteca específica, as quais certamente não se enquadram em padrões preestabelecidos (FIGUEIREDO, 1992).

Conforme Ferreira (2004, p.3), "o serviço de referência é o processo de identificar as necessidades de informação de um utilizador, facultar-lhe o acesso aos recursos e fornecer-lhe apoio apropriado para satisfação das suas necessidades”.

A dinâmica do processo de referência geralmente inclui duas fases: uma relacionada à natureza do problema e outra às ações, decisões e caminhos percorridos pelo bibliotecário. A primeira fase, ou fase preliminar, relacionada à natureza do problema, envolve quatro etapas: o problema, a necessidade de informação, a questão inicial e a questão negociada. A segunda fase, relacionada às ações, decisões e caminhos percorridos pelo bibliotecário durante o processo, envolve quatro etapas: a estratégia de busca, o processo de busca, a resposta e a solução (GROGAN, 2001).

Na estrutura das bibliotecas universitárias as mudanças são percebidas com maior clareza por decorrência do desenvolvimento tecnológico na prestação de serviços de informação, a exemplo dos recursos de armazenamento e recuperação da informação, os quais devem estar cada vez mais voltados às necessidades dos usuários e não somente as determinações técnicas (NUNES; SANTOS, 2007).

Existem diferentes processos de referência em bibliotecas universitárias. Cada vez mais, o perfil do usuário destas bibliotecas exige uma reformulação das funções do bibliotecário de referência devido ao advento das tecnologias e suas formas de 
disponibilizar a informação. É preciso que o bibliotecário ensine também a utilizar os recursos informacionais existentes na biblioteca enquanto mediador do conhecimento. Desta forma, Almeida Júnior (2003, p. 60) descreve que:

o bibliotecário de referência deverá analisar a demanda do usuário, entendê-la e transformá-la dentro de parâmetros passíveis de recuperação, ou seja, a linguagem documentária, a linguagem artificial utilizada pela biblioteca. A partir dessa análise, fará uso dos produtos documentários, de estratégias de busca e de ferramentas de recuperação para levar o usuário até o documento que poderá satisfazer sua necessidade informacional (ALMEIDA JÚNIOR, 2003, p.60).

Dentre as novas funções do bibliotecário de referência e de acordo com a demanda do usuário, entende-se a necessidade de um Processo de Referência Educativo (PRE) que proporcione treinamentos em bases de dados, palestras educativas com o uso dos recursos informacionais, além das visitas programadas com usuários de diferentes áreas do conhecimento. Estas habilidades educativas já são executadas pelos bibliotecários de referência de diversas bibliotecas universitárias, auxiliando o usuário na busca e aquisição do conhecimento especializado. Dependendo da necessidade de informação do usuário, pode-se distinguir qual o processo de referência a ser utilizado pelo bibliotecário, tais como: Processo de Referência Tradicional (PRT), Processo de Referência Virtual (PRV) e Processo de Referência Educativo (PRE), conforme o quadro 1, apresentado a seguir elaborado com base nas teorias de Dudziak, Gabriel e Villela (2000); Oliveira e Bertholino (2000); Grogan (2001): 
Quadro 1: Processos de Referência

\begin{tabular}{|c|c|c|}
\hline $\begin{array}{c}\text { Processo de } \\
\text { Referência } \\
\text { Tradicional - PRT } \\
\end{array}$ & $\begin{array}{l}\text { Processo de Referência } \\
\text { Virtual - PRV }\end{array}$ & $\begin{array}{l}\text { Processo de Referência } \\
\text { Educativo - PRE }\end{array}$ \\
\hline $\begin{array}{l}\text { 1.PROBLEMA } \\
\text { Etapa em que o usuário tem } \\
\text { anseio de conhecer, mas tem } \\
\text { pouca clareza sobre o que } \\
\text { precisa. }\end{array}$ & $\begin{array}{l}\text { 1.PROBLEMA OU } \\
\text { QUESTÃO DE REFERÊNCIA } \\
\text { Identificação das necessidades de } \\
\text { informação do usuário virtual através } \\
\text { da questão inicial recebida por e-mail. }\end{array}$ & $\begin{array}{l}\text { 1.PROBLEMA } \\
\text { Identificação das necessidades de } \\
\text { informação do usuário ou grupo } \\
\text { de usuários, através de entrevista } \\
\text { prévia. }\end{array}$ \\
\hline $\begin{array}{l}\text { 2.NECESSIDADE DE } \\
\text { INFORMAÇÃO } \\
\text { Usuário sabe que precisa de } \\
\text { informação e sozinho ou com } \\
\text { auxílio do bibliotecário procura } \\
\text { definir sua questão inicial. }\end{array}$ & $\begin{array}{l}\text { 2.NEGOCIAÇÃO DA QUESTÃõ } \\
\text { Reformulação da questão inicial } \\
\text { enviada pelo usuário, se necessário. }\end{array}$ & $\begin{array}{l}\text { 2.ROTEIRO } \\
\text { Seleção das fontes a serem } \\
\text { acessadas e demonstradas (acesso } \\
\text { local ou remoto); } \\
\text { Seleção de palavras-chave } \\
\text { pertinentes ao tema ou área de } \\
\text { interesse do usuário ou grupo de } \\
\text { usuários. }\end{array}$ \\
\hline $\begin{array}{l}\text { 3.QUESTÃO INICIAL } \\
\text { Usuário apresenta sua questão } \\
\text { em linguagem natural }\end{array}$ & $\begin{array}{l}\text { 3.ESTRATÉGIA DE BUSCA } \\
\text { Elaboração de roteiro com a seleção } \\
\text { das fontes de informação que serão } \\
\text { pesquisadas; Seleção de palavras- } \\
\text { chave ou expressões de busca; } \\
\text { Busca em si (recuperação da } \\
\text { informação). }\end{array}$ & $\begin{array}{l}\text { 3.ENSINO/APRENDIZAGEM } \\
\text { Ensino sobre o acesso e uso das } \\
\text { fontes e recursos de informação de } \\
\text { interesse do usuário ou grupo de } \\
\text { usuários. }\end{array}$ \\
\hline $\begin{array}{l}\text { 4.QUESTÃ̃ NEGOCIADA } \\
\text { Reformulação da questão } \\
\text { inicial apresentada pelo } \\
\text { usuário, se necessário. }\end{array}$ & $\begin{array}{l}\text { 4.RESPOSTA } \\
\text { Elaboração da resposta; Transmissão e } \\
\text { comunicação dos resultados obtidos } \\
\text { (referências e/ou links de acesso } \\
\text { pertinentes). }\end{array}$ & $\begin{array}{l}\text { 4.FEEDBACK } \\
\text { Momento em que bibliotecário e } \\
\text { usuário ou grupo de usuários } \\
\text { avaliam o ensino-aprendizagem. }\end{array}$ \\
\hline $\begin{array}{l}\text { 5.ESTRATÉGIA DE BUSCA } \\
\text { Seleção das fontes ou recursos } \\
\text { de informação apropriados }\end{array}$ & $\begin{array}{l}\text { 5.AVALIAÇÃO } \\
\text { Confirmação e avaliação do usuário } \\
\text { sobre resposta enviada por e-mail. }\end{array}$ & \\
\hline $\begin{array}{l}\text { 6.BUSCA } \\
\text { Acesso às fontes e recursos } \\
\text { informacionais pertinentes } \\
\text { (presencial ou remoto). }\end{array}$ & & \\
\hline $\begin{array}{l}\text { 7.A RESPOSTA } \\
\text { Fornecimento das fontes ou da } \\
\text { relação de referências a serem } \\
\text { consultadas. }\end{array}$ & & \\
\hline $\begin{array}{l}\text { 8.A SOLUÇÃO } \\
\text { Acordo entre bibliotecário e } \\
\text { usuário sobre a resposta obtida. }\end{array}$ & & \\
\hline
\end{tabular}

Fonte: Rostirolla (2006)

Um dos processos diferenciais na mediação entre o bibliotecário e o usuário é a transformação da linguagem natural utilizada pelo usuário, em linguagem documentária exigida na busca especializada. O bibliotecário de referência precisa ter a arte de pesquisar através dos seus conhecimentos, experiências, habilidades e criatividade. 0 conhecimento gerado durante o processo de entrevista do usuário requer do profissional, técnicas de pesquisa avançada e específica com base nos descritores mencionados e/ou capturados neste processo de interação entre o bibliotecário e o usuário.

Este processo inicia a identificação do problema, ou seja, a identificação das necessidades do usuário, gerando a oportunidade do ensino/aprendizagem no serviço de 
referência. Considera-se que o serviço de referência educativo em bibliotecas universitárias é uma inovação, é agente facilitador para obtenção da informação, uma vez que o usuário ganha autonomia para a pesquisa e isso pode facilitar para que o serviço seja consumido sem a intervenção de um terceiro, ao longo do processo (PINTRO; INOMATA; RADOS, 2014).

Observa-se atualmente, que há uma mudança no perfil do serviço de referência nas bibliotecas universitárias, o qual incorpora as novas tecnologias de acesso à informação às diversas áreas do conhecimento, saindo de um simples acesso às coleções da biblioteca para um universo do conhecimento científico e tecnológico além dos muros da universidade. Todo o processo de criação do conhecimento incorpora uma investigação da necessidade de informação para posterior externalização desse conhecimento.

\section{METODOLOGIA}

Esta pesquisa caracteriza-se, do ponto de vista da abordagem do problema, do objetivo, e dos procedimentos técnicos, respectivamente, como: pesquisa qualitativa, descritiva e estudo de caso. Qualitativa, por exigir a interpretação dos fenômenos e a atribuição de significados. (GIL, 2009). Assim, esta pesquisa buscou analisar o processo de criação do conhecimento, durante a realização do serviço de referência em uma determinada biblioteca universitária. Descritiva, por descrever as características da população e do fenômeno estudado estabelecendo relações entre eles. E também por fazer uso de técnica padronizada de coleta de dados, o questionário. E estudo de caso, por envolver um estudo profundo do processo o processo de criação de conhecimento durante a atividade de serviço de referência de uma dada biblioteca.

A pesquisa foi aplicada na Biblioteca Universitária, denominada Biblioteca Central Zila Mamede (BCZM), localizada na Universidade Federal do Rio Grande do Norte (UFRN), cuja população estudada constituiu-se da equipe de profissionais (2 assistentes administrativos, 3 bibliotecários e 3 estagiários), que atuam na atividade de serviço de referência.

Foi realizada uma visita técnica na BCZM, com a finalidade de coletar dados relevantes para o desenvolvimento desta pesquisa. 0 instrumento de coleta de dados empregado foi um questionário, adaptado de Rostirolla (2009), composto por questões de múltipla escolha e questões abertas. 
A amostra estudada foi equivalente a 7 pessoas, pois um membro da equipe encontrava-se gozando férias. 0 questionário foi direcionado a todos os 7 profissionais integrantes da equipe de serviço de referência, onde obtivemos uma taxa de resposta equivalentes a $100 \%$.

De posse dos dados coletados, partiu-se para a organização e análise destes. Sabese que, nesta etapa, o pesquisador organiza e tabula os dados para posterior interpretação e correlação do material coletado com o propósito da pesquisa.

De acordo com Ludke e André (1986, p.45):

A tarefa de análise implica, num primeiro momento, a organização de todo o material, dividindo-o em partes, relacionando essas partes e procurando identificar nelas, tendências e padrões relevantes. Num segundo momento essas tendências e padrões são reavaliados buscandose relações e inferências num nível de abstração mais elevado.

Assim, a análise abarca a execução de inferências acerca das questões apontadas na pesquisa, extraindo dos questionários, indicadores que permitiram analisar o processo de criação de conhecimento organizacional durante a atividade de serviço de referência.

Para facilitar a tabulação dos dados, criou-se um arquivo de dados eletrônicos no aplicativo Excel da Microsoft. E assim, organizaram-se as informações, relacionando as respostas referentes a cada questão do questionário com os as seguintes categorias estabelecidas:

Quadro 2: Categorias estabelecidas

\begin{tabular}{|l|l|}
\hline Categoria 1 & $\begin{array}{l}\text { Fontes de informação internas e externas (formais e informais) utilizadas pela } \\
\text { equipe que atuam no serviço de referência para responder as questões } \\
\text { apontadas pelos usuários; }\end{array}$ \\
\hline Categoria 2 & $\begin{array}{l}\text { Conhecimentos e habilidades necessárias para a atuação plena no serviço de } \\
\text { referência; }\end{array}$ \\
\hline Categoria 3 & $\begin{array}{l}\text { Conversão do conhecimento tácito para explícito, apoiado nos modos 4 modos } \\
\text { de conversão existente: socialização, externalização, combinação e } \\
\text { internalização, no âmbito da prática do serviço de referência; }\end{array}$ \\
\hline Categoria 4 & $\begin{array}{l}\text { Condições e fatores que interferem no processo de criação de conhecimento, } \\
\text { durante a atividade de serviço de referência. }\end{array}$ \\
\hline
\end{tabular}

Fonte: Elaboração das autoras

Concluída a tabulação dos dados, iniciou-se a etapa de análise. Essa etapa ocorreu amparada no escopo da pesquisa, ou seja, conforme os objetivos específicos estabelecidos neste artigo. Para cada resposta obtida, contextualizou-se com a literatura, conforme consta no tópico a seguir. 


\section{RESULTADOS}

\subsection{Caracterização da biblioteca e dos profissionais que atuam na atividade de serviço de referência}

A Biblioteca Universitária, doravante denominada de Biblioteca Central Zila Mamede (BCZM), da Universidade Federal do Rio Grande do Norte (UFRN) foi fundada em 1959. É responsável pela administração, planejamento, coordenação e fiscalização das atividades do Sistema de Bibliotecas (SISBI) da referida Universidade.

Tem a missão de fornecer suporte informacional, em todos os formatos, às atividades de ensino, pesquisa e extensão da UFRN.

Dispõe dos serviços de: empréstimo domiciliar, orientação bibliográfica, levantamento bibliográfico, visitas programadas, normalização de documentos, catalogação na fonte, comutação bibliográfica, ISSN, ISBN, direitos autorais, empréstimo entre bibliotecas, reserva dos espaços da biblioteca, acesso a internet e reprografia de documentos.

Possui uma área de aproximadamente 9.000,00 $\mathrm{m}^{2}$, com uma videoteca, auditório, mini-auditório, hall para exposições, sala de Autores Norte-Riograndenses, sala de máquinas leitoras/copiadoras de multimeios, sala climatizada para estudos individuais e em grupos, sala de obras raras, laboratório de informática e de acessibilidade, mesas para estudo em grupo, 4 totens para acesso ao catálogo on line, cantina e jardins internos.

No que se refere à estrutura organizacional, a BCZM possui 4 divisões: divisão de apoio ao usuário, divisão de seleção e aquisição, divisão de apoio tecnológico e divisão de processos técnicos.

Esta pesquisa foi aplicada no setor de referência, que pertence a divisão de apoio ao usuário, assim descrevem-se as características dos profissionais que ali atuam, como segue:

Para atender às necessidades de informação da comunidade universitária, o setor de referência conta com uma equipe composta por 3 bibliotecários, 2 assistentes administrativos e 3 estagiários do curso de graduação em Biblioteconomia. '

Quanto a formação acadêmica dos bibliotecários, o setor conta com 2 mestres e 1 especialista. Já os assistentes administrativos possuem formação em gestão pública e em arquitetura e urbanismo. A segunda formação acadêmica citada agregou valor ao referido setor, pois o assistente administrativo - arquiteto urbanista dispõe de 
habilidade em manusear programas computacionais gráficos e entre outros conhecimentos que a referida graduação proporciona. Assim, junto com a equipe de bibliotecários e estagiários, o assistente desenvolve tutoriais, folders e entre outros materiais informativos, com o objetivo de aproximar os usuários às fontes de informação.

Com isso, pode-se inferir que tal formação diferenciada agrega valor aos produtos e serviços oferecido pelo setor estudado. E quanto ao tempo de trabalho no referido setor, a pesquisa apontou que, há bibliotecários que trabalham há cerca de 1 ano e também há profissionais que atuam há mais de 30 anos. Os assistentes administrativos trabalham no setor há cerca de 5 anos e os estagiários há cerca de aproximadamente 1 ano.

De acordo com o tempo de atuação de cada membro do setor, é de se esperar que a equipe estudada possua um certo conhecimento organizacional e que tenham construído conhecimentos tácitos acerca das atividades preestabelecidas, processos internos, normas e valores que regem o sistema de bibliotecas.

Quanto à faixa etária, a equipe possui entre 20 e 60 anos, sendo composta por 04 mulheres e 3 homens. Diante dessa informação, pode-se inferir que a equipe que trabalha na atividade de serviço de referência é constituída por três gerações, ou seja, trata-se de uma equipe heterogênea.

É oportuno pontuar também que, a interação dessa equipe heterogênea gera, em alguns momentos, conflitos, em função da visão e percepção diferenciada. Mas, por outro lado é inegável que essa convivência promova possibilidade ímpar de aprendizagem. Conforme foi observado, os membros mais velhos orientam os mais jovens, no tocante a cultura organizacional da BCZM; os membros mais jovens servem de "modelo" para que os mais velhos observem a capacidade destes em adaptar-se, ousar e reinventar-se a cada momento, e ainda aprendem com eles a explorar as potencialidades das TICs, e assim obtêm mais êxito na realização de suas atividades laborais, o que faz com que a BCZM disponha de maior agilidade nas respostas dos problemas imediatos, referentes ao serviço de referência.

\subsection{Fontes de informação internas e externas (formais e informais) utilizadas pela equipe que atuam no serviço de referência para responder as questões apontadas pelos usuários}

As fontes de informação são canais onde são extraídas informações importantes 
para a formulação de ideias e obtenção de conhecimentos.

Considerando as fontes de informação internas formais utilizadas durante a atividade de serviço de referência, a pesquisa apontou que as mais utilizadas pela equipe são: os repositórios da UFRN (71,42\%); materiais informacionais do acervo (livros, dicionários, enciclopédias, jornais, dissertações, etc.) (71,42\%); catálogos, folders, folhetos da UFRN (57,14\%); portal de periódicos da UFRN (42,85\%), manuais de serviços (42,85\%); anotações pessoais (42,85\%), e os e-mails trocados pela equipe $(42,85 \%)$.

Quanto às fontes de informação internas informais mais utilizadas durante a atividade estudada, a pesquisa revela que são: experiências compartilhadas com os membros da equipe (85,74\%); equipe de atendimento ao usuário (circulação, coleções especiais, repositórios institucionais) (85,74\%); conversas de corredor como outros profissionais da biblioteca $(71,42 \%)$; contato telefônico com profissionais da biblioteca $(57,14 \%)$ e redes sociais com profissionais da biblioteca $(42,85 \%)$.

No que tange às fontes de informação externas formais, mais utilizadas durante a atividade de serviço de referência, de acordo com a pesquisa, as mais utilizadas são: Portal de periódicos da CAPES (85,74\%); sites da internet (documentos governamentais, legislações, tratados, patentes, normas técnicas e etc.) (57,14\%); repositórios de outras instituições (42,85\%); catálogo de outras bibliotecas $(42,85 \%)$ e troca de e-mails com profissionais de outras instituições $(42,85 \%)$.

Em se tratando das fontes externas informais, a pesquisa aponta que durante a atividade supracitada, a equipe faz uso de: Redes sociais com profissionais de outras instituições (42,85\%); grupos de discussão na WhatsApp com profissionais de outras instituições $(42,85 \%)$ e dos conhecimentos obtidos por meio de Palestras, Seminários/Congressos/Encontros profissionais (28,57\%).

\subsection{Conhecimentos e habilidades necessárias para a atuação plena no serviço de referência}

De acordo com a pesquisa, para que o serviço de referência ocorra plenamente na BCZM, faz-se necessário que a equipe disponha dos seguintes conhecimentos e habilidades: conhecimento do acervo; das fontes de informação, tais como: portal de periódicos, repositórios, sites governamentais, patentes e entre outros canais de informação; das linguagens documentárias; do perfil do usuário real da biblioteca e 
idiomas. No tocante às habilidades é preciso ter o domínio das tecnologias da informação; técnicas de entrevista; aptidão para elaborar estratégias de busca, proatividade, dinamismo, flexibilidade e tato com as pessoas.

\subsection{Conversão do conhecimento tácito para explícito apoiado nos 4 modos de conversão}

A pesquisa apontou, com (100\%) das respostas dos respondentes, que o conhecimento individual criado durante a atividade de serviço de referência é difundido entre eles, fazendo parte da memória da organização. Acredita-se que isso acontece devido ao pequeno número de membros que integram a equipe, pois se tem um maior controle sobre o conhecimento e sabe-se, quando e para quem disseminá-lo. A equipe pequena, ainda facilita o fluxo de conhecimento entre os eles, bem como, facilita que os modelos mentais e as experiências sejam compartilhadas.

Quanto aos meios utilizados pelo setor estudado para disponibilizar conhecimentos criados durante a atividade de serviço de referência, a pesquisa revelou que as reuniões presenciais com a equipe (conhecimento tácito e explícito), treinamentos (conhecimento tácito e explícito), interação individual ou conversas (conhecimento tácito), intranet/internet e emails (conhecimento explícito) são os meios utilizados pela equipe.

Através desses meios utilizados, é possível identificar o tipo de conhecimento que permeia o setor estudado. Esses resultados confirmam o pensamento de Nonaka e Takeuchi (1997), que destacam que os indivíduos trocam e combinam conhecimentos através de meios como: documentos, reuniões, conversas ao telefone ou redes de comunicação computadorizadas, onde estas últimas se forem utilizadas de forma criativa, possuem importante papel para facilitar o modelo de combinar conhecimentos.

A pesquisa apontou com unanimidade nas respostas (100\%), que durante a atividade de serviço de referência, os membros interagem buscando compartilhar seus conhecimentos tácitos, por meio de: emprego de palavras, frases, uso de figuras e desenhos.

A divisão estudada identifica quais os conhecimentos que precisam ser criados, armazenados e transferidos. Esses conhecimentos são acerca das técnicas empregadas para recuperar informações, estratégias de buscas e bases de dados.

Para importar conhecimentos, a divisão interage com o ambiente externo, sendo 
agentes desse processo: bibliotecários e profissionais de outras instituições. 0 conhecimento importado antes de ser armazenado passa por uma seleção. Essa seleção obedece a critérios simples como: relação com as atividades desenvolvidas e com as estratégias e objetivos do setor.

Para que o conhecimento seja criado, depende de algumas ações, entre as quais se destacam: registro (ou armazenamento) e o acesso (disponibilização). A pesquisa confirmou que $(85,74 \%)$ dos respondentes assinalaram que o conhecimento é criado na mente das pessoas. Enquanto que (14,26 \%) assinalou que registra seu conhecimento em seu caderno pessoal (agenda) e (14,26 \%) assinalou que utiliza os repositórios institucionais ou arquivos específicos em meio eletrônico. Porém, na alternativa "Outros", (57,14 \%) dos respondentes acrescentaram que usam também a caixa de email, o manual do setor, redes sociais, o serviço digital de referência além de outros documentos impressos existentes.

Outro ponto importante para a organização que cria conhecimento se refere à capacidade de seus colaboradores absorverem conhecimento, ou seja, internalizar o conhecimento. Quando o conhecimento explícito é internalizado (transformado em tácito) sob a forma de modelos mentais ou conhecimento técnico compartilhado, as experiências através da socialização, externalização e combinação tornam-se ativos valiosos (NONAKA; TAKEUCHI, 1997; 2008).

Nesta perspectiva, a pesquisa apontou com unanimidade nas respostas (100\%) que a equipe do setor estudado absorve o conhecimento recém-criado por meio de: reuniões e conversas informais.

Assim, foi possível constatar que durante a atividade de serviço de referência ocorre as quatro fases de criação do conhecimento, conforme segue:

Socialização: o setor estudado a fim de criar novos conhecimentos tácitos, promove reuniões; interações face a face; encontro na sala de café; interação com o ambiente interno e externo e treinamentos, para que as experiências, habilidades pessoais e modelos mentais dos membros da equipe sejam compartilhadas.

Externalização: o setor transforma o conhecimento tácito em explícito, nesta fase os membros realizam tal ação, por meio de emprego de palavras, frases, uso de figuras, desenhos, diagramas e emprego da linguagem figurativa como metáfora e analogia. 0 setor faz uso das TICs para dinamizar diálogos e reflexões coletivas, pois estas oferecem recursos de interatividade. 
Combinação: o setor transforma o conhecimento explícito em explícito, nesta fase, os membros trocam e combinam um conjunto de diferentes conhecimentos por meio de documentos, reuniões, conversas ao telefone ou redes de comunicação computadorizadas. Porém, a pesquisa demonstrou que isso precisa ser melhorado, pois a maior parte do conhecimento criado não é registrado, ficam armazenados na mente das pessoas.

Internalização: a divisão transforma o conhecimento explícito em tácito, nesta fase os membros obedecem à filosofia do "aprender fazendo". Apesar de uma parte pequena do conhecimento criado ser registrado, a equipe faz uso destes documentos, que relatam algumas experiências individuais, e este conhecimento para a ser incorporado a sua base de conhecimento. Após a incorporação do conhecimento, o conhecimento tácito recém-criado é socializado com os outros membros do setor, dando início assim a uma nova espiral de criação do conhecimento organizacional.

Cada uma dessas fases descreve o processo de conversão do conhecimento tácito e explícito visando à criação do conhecimento organizacional. Onde é possível confirmar que o conhecimento criado organizacionalmente acontece amparado na espiral proposta por Nonaka e Takeuchi $(1997 ; 2008)$.

\subsection{Condições e fatores que interferem no processo de criação de conhecimento, durante a atividade de serviço de referência}

A pesquisa apontou que as cinco condições favoráveis para a criação do conhecimento organizacional apresentadas por Nonaka e Takeuchi, perpassam o ambiente organizacional da divisão de processos técnicos, conforme segue:

Intenção: esta condição atingiu (100\%) das respostas, sinalizando que as metas e os objetivos da divisão estudada são comunicados a todos os membros, que ali atuam.

Autonomia: esta condição atingiu $(85,74 \%)$ das respostas. Este resultado indica que as decisões são democráticas, o que pode contribuir para o processo de criatividade.

Flutuação e o caos criativo: esta condição atingiu (28,57\%) das respostas, deixando evidente que a equipe estudada não é estimulada com metas desafiadoras nem vislumbram o ambiente organizacional em "sentido de crise" para promover a criação de novos conhecimentos.

Redundância: esta condição atingiu (100 \%) das respostas, demonstrando que a equipe estudada interage com os membros de outras divisões da biblioteca, o que de 
acordo com Nonaka e Takeuchi (1997) permite que a informação e conhecimento sejam tratados sob diferentes perspectivas possibilitando, por exemplo, o surgimento de ideias sob um novo ponto de vista. Tal interação revela que na divisão estudada não existem barreiras para o aprendizado organizacional e transferência do conhecimento.

Requisito e variedade: esta condição atingiu (85,74 \%) das respostas, demonstrando que a equipe estudada, geralmente possui conhecimentos, habilidades e competências para atender as necessidades de seu cargo ou função. Sobre isso, é oportuno frisar que UFRN investe continuamente na capacitação dos servidores, oferecendo vários cursos e treinamentos, visando o desenvolvimento e crescimento institucional.

Retomando ao processo de criação de conhecimento, sabe-se que as ferramentas da tecnologia da informação e da comunicação (TICS) exercem um papel importante neste processo. A pesquisa apontou que as ferramentas utilizadas diariamente, pela equipe durante a atividade de serviço de referência são: email e telefone, ambos com (71,42\%) e Facebook, intranet e WhatsApp, ambas com (42,85\%).

A pesquisa ainda apontou que a equipe estudada não faz uso das seguintes TICS: Blogs e Twitter (100\%).

Para findar este tópico é importante ressaltar que a TI não é tudo no processo de criação de conhecimento. Mas é parte desse processo. Portanto, é necessário que a equipe estudada esteja engajada, ciente e focada em um propósito comum de colaboração, fazendo bom uso da TI para atingir os objetivos definidos pelo setor de referência.

\section{CONCLUSÃO}

Este estudo revelou que o processo de criação de conhecimento depende de dados, informações e conhecimentos oriundos do meio interno e externo da biblioteca. O conhecimento, resultante de um processo constante de interação, para ser ampliado organizacionalmente, necessita ser compartilhado e difundido entre a equipe do setor de referência.

As fontes de informação, quando bem exploradas, são ótimos meios de aquisição de conhecimentos, tornando-se um diferencial de qualidade na efetivação da atividade de serviço de referência. 
A conversão do conhecimento tácito e explícito auxilia no êxito da execução da atividade de serviço de referência, por meio de composição heterogênea da equipe de trabalho e utilização das TICs como um importante meio de armazenagem e disponibilização de conhecimento. Contextos adequados compostos por diversas condições e fatores podem facilitar esse processo, fomentando o fluxo de informação e conhecimento ao longo da execução da atividade estudada.

As ferramentas da tecnologia da informação e comunicação contribuem na comunicação, colaboração e interação entre a equipe na medida em que possibilitam a troca de informações, ideias e experiências, alavancando assim, o processo de criação de conhecimento.

\section{REFERÊNCIAS}

ALMEIDA JÚNIOR, O. F. Biblioteca pública: avaliação de serviços. Londrina: Eduel, 2003.

BAUMAN, Z. Vida líquida. Rio de Janeiro: Jorge Zahar, 2007.

BUKOWITZ, W. R.; WILLIAMS, R. L. Manual de gestão do conhecimento: ferramentas e técnicas que criam valor para a empresa. Tradução Carlos Alberto Silveira Netto Soares. 2. ed. rev. Porto Alegre: Bookman, 2002.

CASTELLS, M. 0 poder da identidade. Lisboa: Fundação Calouste Gulbenkian, 2003.

CHOO, C. W. A organização do conhecimento: como as organizações usam a informação para criar significado, construir conhecimento e tomar decisões. São Paulo: Senac, 2006.

DAVENPORT, T. H.; PRUSAK, L. Conhecimento empresarial: como as organizações gerenciam o seu capital intelectual. 12. ed. Rio de Janeiro: Campus, 2003.

DE MASI, D. 0 futuro do trabalho: fadiga e ócio na sociedade pós-industrial. 9. ed. Rio de Janeiro: José Olympio, 2006.

DRUCKER, P. F. Post-capitalist society. Butterworth-Heinemann; Oxford, 1994.

FERREIRA, M. I. G. M. High tech/high toch: serviço de referência e mediação humana. In: CONGRESSO NACIONAL DE BIBLIOTECÁRIOS, ARQUIVISTAS

E DOCUMENTALISTAS, 8, 2004, Estoril, Portugal. Anais...Estoril: Associação Portuguesa de Bibliotecários, Arquivistas e Documentalistas, 2004.

FIGUEIREDO, N. M. Serviços de referência e informação. São Paulo: Polis, 1992.

FRANCISCO, A. C. Aquisição de competências no estágio curricular supervisionado: o caso dos cursos de engenharia do CEFET-PR. Florianópolis, 2003. 181 p. Tese (Doutorado em Engenharia de Produção) Programa de Pós-Graduação em Engenharia de Produção, Centro Tecnológico, Universidade Federal de Santa Catarina, Florianópolis, 2003.

GIDDENS, A. As consequências da modernidade. São Paulo: Unesp, 1991. 
GIL, A. C. Como elaborar projetos de pesquisa. São Paulo: Atlas, 2009.

GOUVEIA, L. M. B. Sociedade da informação: notas de contribuição para uma definição operacional. 2004. Disponível em

<http://www2.ufp.pt/ lmbg/reserva/lbg socinformacao04.pdf>. Acesso em: 15 nov. 2011.

GROGAN, D. J. A prática do serviço de referência. Brasília: Briquet de Lemos, 2001.

HALL, S. A identidade cultural na pós-modernidade. Rio de Janeiro: DP\&A, 2001.

LIPOVETSKY, G. Os tempos hipermodernos. São Paulo: Barcarolla, 2004.

LYOTARD, Jean-François. A condição pós-moderna. Rio de Janeiro: José Olympo, 1979.

LUDKE, M.; ANDRÉ, M. Pesquisa em educação: abordagens qualitativas. São Paulo: EPU, 1986.

MACHLUP, F. The production and distribution of knowledge in the United States. New Jersey, Princeton University Press, 1962.

MARTENSSON, M. A critical review of knowledge management as a management tool. Journal of Knowledge Management, v.4, n. 3, p. 204-216, 2000.

NASCIMENTO, N. J.; NEVES, J. T. dos R. Uma investigação de sites e documentos sobre gestão do conhecimento na World Wide Web. In: SEMINÁRIO LATINO- IBEROAMERICANO DE GESTIÓN TECNOLÓGICA, 8., 1999: Valência-Espanha)

Anais... Valência, 1999.

NONAKA, I. ; TAKEUCHI, H. Criação de conhecimento na empresa: como as empresas japonesas geram a dinâmica da inovação. Rio de Janeiro: Campus, 1997.

NONAKA, I. ; TAKEUCHI, H. Gestão do conhecimento. Porto Alegre: Bookman, 2008. 319p.

NUNES, S. ; SANTOS, L. Políticas de informação e aprendizagem organizacional: desafios para a implantação de novas tecnologias em bibliotecas universitárias. Comunicação e Informação, v. 10, n. 1, p. 73-81, jan./jun. 2007.

PINTRO, S. ; INOMATA, D. O. ; RADOS, G. J. V. Serviço de referência de bibliotecas universitárias: tradicional e educativo. Tendências da Pesquisa Brasileira em Ciência da Informação, v. 7, n. 2, 2015.

POLANYI, M. The tacit dimension. Gloucester: Peter Smith, 1966.

RAMOS, A. G. A nova ciência das organizações. Rio de Janeiro: FGV, 1989.

ROBBINS, S. P. Administração: mudanças e perspectivas. São Paulo: Saraiva, 2000.

ROSTIROLLA, G. Gestão do conhecimento no serviço de referência em bibliotecas

universitárias: uma análise com foco no processo de referência. 2006. 174 f. Dissertação (Mestrado em Ciência da Informação) - Programa de Pós-Graduação em Ciência da Informação da Universidade Federal de Santa Catarina, Florianópolis, 2006.

SANTOS, N. Gestão do conhecimento organizacional. EGC/CTC/UFSC. Florianópolis, 2005. 
SHIN, M. ; HOLDEN,T. ; SCHMIT, R. A. From knowledge theory to management practice: towards an integrated approach. Information Processingand management, v. 37, p. 335 - 355, 2001.

STEWART, T. A. Capital intelectual: a nova vantagem competitiva das empresas. 9. ed. Rio de Janeiro, RJ: Campus, 1998. 237 p.

SVEIBY, K. E. A nova riqueza das organizações: gerenciando e avaliando patrimônios de conhecimento. Rio de Janeiro: Campus, 2008.

Recebido em: 24 de maio de 2016 Aceito em: 15 de setembro de 2017 